steam and the apparatus for generating it. Before that time arrives, and some form of gas engine (including oil engines) arrive, a distinctly new departure will have to be made equivalent to that of the separate condenser of Watt.

The last paper in the list, that of Mr. G. H. Bryan on bulkheads, was in some respects the most promising and most sug. gestive of the meeting. The bulkhead question has been troubling the most thoughtful of our naval architects for some time past. Dr. Elgar attacked the question some time back in a paper he read before the Institution, and Mr. Martell also read a memoir on the subject. Some time ago a strong Government committee was appointed to consider the problems involved in this matter, and a report was issued. Rightly or wrongly, some naval architects are not satisfied with the position in which the report left the question. It is considered by many of the more thoughtful that a more scientific method of dealing with the problem should be evolved. Mr. Bryan, who is a Cambridge mathematician of high reputation at his University, has been led to take the matter up, and the present paper is an effort to bring higher mathematics to the aid of the solution of the question. The paper, however, contains nothing that need appal any naval architect or engineer who can lay fair claim to the title, and it is eminently practical. The similes selected by the author are of the simplest nature; indeed, the memoir reads more like a contribution from the pen of the late Mr. Froude, who was a very prince of lucidity and simplicity. We are reluctantly obliged, through want of space, to treat this paper as we have the others read at this meet. ing, and only give a suggestion of its scope, referring our readers to the Transactions of the Institution for fuller details. Mr. Bryan attacks the theory, still held by many engineers, that the plate may be regarded as consisting of a series of parallel strips supporting pressure by their tensions. Euler's and Bernouilli's early theories have been abandoned by mathematicians, and Mr. Bryan is now trying to persuade engineers to do the same in effect in giving up the "parallel strip" illustration. The matter affords an excellent txample of the manner in which the student of higher mathematics may assist the engineer. We may add that it is proposed to discuss the subject at the next meeting of the Institution to be held next spring, and doubtless Mr. Holmes, the secretary of the Institution, would forward a copy of the paper to any one wishing to take part in the dis. cussion. The address of the Institution is 5, Adelphi Terrace, Strand.

\section{SOCIETY OF CHEMICAL INDUSTRY.}

THE Annual General Meeting of the Society of Chemical InI2, when Sir John Evans, K.C. B., Treas. R.S., delivered his Presidential address as follows :-

"When I look at the list of those who in past years have occupied the Presidential chair of this Society, all of them men eminent in the departments of either theoretical or practical chemistry, or, indeed, of both, I cannot but feel my own insufficiency to succeed them in worthily fulfilling the duties of this post. I am, indeed, tempted to inquite how and why it was, that, in accordance with the pressing invitation of some members of the Council, I ever consented to allow myself to be placed in nomination as your President. It certainly was not on the grounds of any fancied chemical attainments; nor was it from my having been in former years associated with any in. dustry that is usually regarded as being specially connected with chemistry. Far less was it in the hope that any remarks that I might be called upon to make while acting as your President could be of any particular interest or value to those who, in all probability, are far better acquainted than I can pretend to be with any subject that properly comes within the scope of such a Society as ours. I believe, however, that the main reason that I had for allowing myself to be brought forward is one that will, to a great extent, palliate my shortcomings in so many of the essential requisites for such an office. It was the hearty and entire appreciation that I felt of the work and aims of such a Society as that of Chemical Industry, that was the prime mover in the case. Whether I regarded the organisation of the Society, with its sections at all the principal centres of chemical operations, each to a certain extent indepenaent, but all working harmoniously together, and forming one powerful and important body, with high objects and aspirations before it ; or whether I looked at it as presenting a bond of union between industries apparently unconnected, while, at the same time, furnishing information of the most useful character to each and all, I could not but recognise it as a body in the highest degree conducive to the public welfare; so that on these, if on no other yrounds, I should have been wanting in public spirit had I stood aloof when others urged me to accept the post of your President.

"It. is, I firmly believe, only by some such cordial co-operation among the different industries of this country as that which our Society has inaugurated, that the commercial position of Great, or Greater, Britain is to be maintained; and the more fully the interdependence between one branch of manufacture and another is recognised and acted upon, the more likely are we, as a whole, to maintain our place in the keen race of competition with other countries.

"A merely cursory glance at our Journal will at once show how numerous are the departments of British industry that are more or less dependent on chemical knowledge, the information given on current literature and the specifications of new patents being arranged under no less than three-and-twenty different heads, many of them embracing several varying occupations. Not a few of these headings would, within my own memory, have conveytd but little meaning even to experts. I need merely carry lack the minds o! some of the elder members of the Society, not only to the days when aniline colours were not and Dr. Perkins was com. paratively unknown, but to the time when lucifer matches hall not been invented, when photography was practically non-existent, and when in most of those industries in which a knowledge of chemistry is now regarded as indispensable, the 'rule of thumb ' reigned absolute.

"I can speak of those old times with some personal feeling, as it is now upwards of fifty years since, that having presumably completed my education, I first entered a paper-mill in order to learn the art and mystery of the manufacture of paper, with which the name of the firm of which I was until lately a member-that of John Dickinson and Co.- - has been so long, and, I may venture to say, so honourably connected. It was, of course, recognised that some knowledge of chemistry was a requisite in such a manufacture, but I must freely confess that our methods were of the rudest, and that it was only as years rolled on, and first esparto fibre, and then the different kinds of wood pulp were introduced into the manufacture, and the various methods and results of sizing studied, that a thorough acquaintance with chemical laws became a sine qua non for those who hoped for success in this branch of industry.

"At the date that I have in view-say 1840 -although rags were the staple material for the manufacture of paper, our consumption of them was but small, and they were principally used by us in producing paper for copper-plate work-steel plates at that time being rarely used-and for the highest class of printing papers. We consumed, however, a large quantity of raw material in the shape of the waste arising in the manufacture of linen and cotton goods, and we had collecting agents at Dundee, Belfast, Bradford, Leeds, and Manchester, who bought the waste upon the spot. At Manchester we had a mill, in which the cotton-waste was cleaned, boiled, and converted into what is known as 'half-stuff,' which was finally bleached and made into paper at our Hertfordshire mills. In that county we had another 'half-stuff' mill, at Rickmansworth, where the linen waste was treated. The boiling was carried on in open keirs, or such as were partially closed, and always at a low pressure, as high pressure boilers for such materials were practically unknown. Most of the waste was twice boiled, first with caustic lime, and secondly with a small amount of soda. The 'shieves,' or woody particles, that were unreduced by the boiling, were got rid of by a long process of screening, or 'devilling, after the 'half-stuff' had been dried so far as possible in hydraulic presses. The material was then bleached in stone chambers by the direct action of chlorine gas, produced on the spot in retorts. At the mills, however, where the 'half-stuff' was converted into paper, the renains of the chlorine had to be washed out, and the final bleaching of the stuff to be effected with bleaching salts. No process for the recovery of the soda used in oiling was then known, and, indeed, the quantity used was so much less than that which is now necessary with esparto, that it would not have paid to recover it. I remember, however, being engaged in some experiments for the recovery of the manganese from the spent liquor of the retorts. Even when first Mr. Routledge introduced the use of esparto fibre no evaporating or recovery

NO. 1238 . VOL. 48 ] 
process was employed, but the double advantage was soon seen of avoiding the nuisance of polluting the streams into which the waste liquors were allowed to flow, and of regaining a quantity of soda at a small cost. With the general adoption of esparto as a material a radical change in the manufacture of paper was effected, and the difficulties in which the industry had been placed by reckles; commercial legislation with regard to foreign rags in a great degree removed.

"What has taken place in the manufacture of paper has been paralleled in numerous other departments of commercial enterprise, and not the least in those connected with the manufacture of chemical products themselves, in many, if not indeed in most of which a complete revolution has been effected within the last fifty years, or even less. It would be a hopeless task to try to indicate the whole of the advances in chemical knowledge that have been made within that period, and yet I am tempted to give some few reminiscences of the condition of the science as exhibited in Brande's Elements of Chemistry, published in May, 1811, exactly twelve months after my first introduction to business, when compared with our knowledge at the present day.

"Chemistry at that time was by no means in its infancy. Its foundations had been securely laid not only on the Continent, but in this country, and the names of Priestley, Cavendish, Scheele, Lavoisier, Davy, Wollaston, and other English investigators were already household words. There were, in $184 \mathrm{I}$, twelve simple non-metallic substances known, from oxygen to boron, including selenium, and forty-three metals from potassium to silicium, including lantanum and thorinum. For all fifty-five, symbols had been arranged, but these were in many respects different from those which are now in universal use. $C$, for instance, stood for chlorine and not for carbon, while B symbolised bromine and not boron. Potassium was designated by $\mathrm{Po}$ and not by $\mathrm{K}$, and sodium by $\mathrm{So}$ and not by $\mathrm{Na}$, while uranium was known as $U \mathrm{rnm}$ and not as $U$.

"The atomic weights of the various substances had been approximately determined, though modern investigations have in some instances materially changed their ratio. Though hydrogen has retained its place as the unit, oxygen is no longer represented by 8 , but by 15.96 , or even less. Sulphur that was then 16 is now 3198 . Selenium, instead of 40 , has now 78 assigned to it; while the number for tellurium has been in. creased fourfold from 32 to 128 , and phosphorus has gone up from I 6 to $30^{\circ} 96$. Whether all our present figures will stand the test of time remains to be seen, and indeed recent researches have shown cause to doubt the accuracy of some of the figures that I have quoted. For myself, as a somewhat profane outsider, I must confess that it would be a source of satisfaction if future investigations should show that the figures now having three or four places of decimals attached to them might more properly be converted into integers, and oxygen came out boldly as 16, and sulphur as 32 . This is, however, a digression.

"Turning to the simple substances and metals of which, as already stated, 12 and 43 respectively were known in 1841 , we find them now slightly increased. Of non-metals we reckon 15, and of metals 48. Some metals, like columbium and glucinum, have dropped out of our list, the latter having now become beryllium, while others, like cæsium, didymium, erbium and rubidium, have come in.

"On the whole, the changes and advances in inorganic chemistry have not been extreme. It is in organic chemistry that what cannot be regarded as anything short of a revolution has taken place. It is not a matter on which I can dilate, but as indicative of what has been going on I may mention that while three volumes have sufficed to Roscoe and Scholemmer for inorganic chemistry, no less than six have already appeared in continuation treating of organic chemistry, and more are to follow; so that the proportions have been reversed which prevailed in the days of Brande, who devoted 367 pages only to organic chemistry, and 1042 to introductory matter and inorganic chemistry.

"But whatever may have been the advances in chemistry within the last fifty years, whether as a pure or an applied science, the extension of its boundaries towards physics in the one direction, and biological studies in the other, is at least as remarkable. While the study of spectrum analysis has rendered most valuable assistance in the chemistry of the constituent substances with which we are familiar upon earth, it has enabled the astronomer to carry his speculations not only to the constitution of the sun and stars, but to that of nebulæ, comets and meteors, and in the hands of Mr. Norman Lockyer and Mr. Huggins may yet lead us to travel with some degree of confidence in paths hitherto untrodden. In the domain of electricity it is hard to say whether that science does not owe nearly as much to chemistry as chemistry does to it. In the practical application of electricity to lighting purposes, chemistry has still to be called on to produce some improved form of secondary battery, and some portable form of primary battery which shall prove of ready application by our miners. It is needless to recall how much our underground workers are indebted to chemistry for their comparative immunity from danger from fire-damp, a danger which the efforts now being made by chemists will, I hope, still further diminish. Electricity has also placed at the command of chemists greater intensity of heat than can be derived from ordinary sources.

"The study of heat, irrespective of electricity, has largely reacted on chemistry, and while the Bessemer process has entirely revolutionised the manufacture of steel, and almost annihilated the distinction in value between that and other forms of iron, the Siemens and other furnaces have led to unprecedented economies in the expenditure of fuel, and at the same time have facilitated the application of heat in various chemical processes. In the other direction-the absence of heat-Prof. Dewar has, during the present year, made most important advances. Although air had previously been liquefied, he has now been able, by means of intense cold alone, to reduce atmospheric air to the liquid condition. His further results, by a combination of enormous pressure and extreme cold, are well known, and now that oxygen and nitrogen have yielded themselves to the advances of science and have been obtained in quantities in a liquid state, it is hard to say that hydrogen is destined always to remain intractable. What may be the ultimate result of the investigations that can now be carried on at temperatures ranging from $100^{\circ}$ to $200^{\circ}$ centigrade below the freezing point of water, it is impossible to foresee. From researches already made in this country and in France, it would appear that most substances under extreme cold are, so to speak, dead, and that their ordinary affinities are in abeyance. Possibly what may be termed 'glacial chemistry' may eventually enlarge our views as to the various properties of matter.

"As to the advances in our knowledge of the chemistry of light, the present condition of photography may testify. When we can take the image of a bullet flying at the rate of 3,000 feet per second, with its accompanying cone of compressed air ; when we can produce photographs which are practically permanent, and when we call in the action of light to engrave our steel or copper plates, and to produce efficient substitutes for woodcuts, we seem to be getting near the limits of the practical application of photography. And yet many of us may remember the days when the daguerrotype was regarded-and justly so -with wonder; and I can myself call to mind a still earlier form of photography, by which natural leaves were reproduced on paper sensitised with a salt of silver, of which I saw specimens in an exhibition at Dresden so long ago as the year I839.

"In the introduction of artificial light much also has been done. It is true that Pall Mall was experimentally lighted by gas in 1807 , but it was not until 1842 that gas found its way into Grosvenor-square and some.other aristocratic quarters of the metropolis. Since that time immense strides have been made in the process of gas manufacture, while, in consequence of the waste products arising in the process having now found commercial uses, great reductions have been made in its cost. At the present time gas has to compete with electricity as an illuminant, while, in many cases, it has been superseded by mineral oils, which are now so abundant and cheap, and of which in this Society the flashing point may be said to be almost a burning question. If, however, gas is losing ground as an illuminant, it seems to be gaining it as a source of power, and there are prospects of a considerable increase in the use for this purpose of hydrogen and its compounds, containing far less carbon than ordinary coal-gas.

"In metallurgy also, in addition to the improvements in the manufacture of steel already mentioned, many noteworthy discoveries have been made. One of the most important of these is perhaps that of the production of aluminium on a cheap scale and in quantities sufficient for various applications to ordinary use. It seems somewhat remarkable that the progress in the use of a metal at once so light and so strong is not more rapid.

"The applications of some of the more modern alloys, such as

No. 1238 , VOL. 48] 
phosphor-bronze, seem also susceptible of considerable further development.

"The extensive manufacture of sodium affords another instance of what was formerly the mere subject of a laboratory experiment, being now conducted upon a commercial scale.

"I may here just glance at the attempts that have been made to produce artificially some of the precious stones that occur in nature. Rubies have been manufactured, not indeed such as could rank as gems, but still such as will serve to "jewel" the pivot-holes in watches; and though the results of attempts to produce the crystallised form of carbon, which is known as the diamond, have as yet had but doubtful success, it does not appear to me that the prospect of producing genuine diamonds under combined heat and pressure is absolutely hopeless.

"Another direction in which great advances have been made, and in which it seems probable that there yet remains something to be discovered, is the grouping of the various elements into small divisions, having more or less analogy the one with the other, and the classification of the atomic weights in one harmonious series. What is known as the Periodic Law of Mendeleeff and of our own Mr. John A. R. Newlands, has sug. gested the possibility that what we now know as metals or elements may have some at present hidden connections between them, so that eventually some of them may prove to be rather compound bodies than strictly elementary substances. This, however, is for the chemistry of the future.

"In organic chemistry, which has been defined to be the chemistry of the hydro-carbons and their derivatives, it is, as I have already observed, that the most wonderful development has taken place within the last half-century. Who, for instance, in I 840 could have foreseen the important part that aniline was to play in dyeing and colouring? It was not, I think, till 1856 that Perkins's mauve was really brought into commercial use, but since that time what a rainbow of colours has been produced from what would have seemed a most unpromising source! How brilliant are their hues, but as yet, in many cases, alas, how fugitive! Regarded from an artistic point of view these colours can hardly be esteemed an unmixed blessing; and even the fabrics of Eastern looms have not escaped their influence.

"Quæ regio in terris nostri non plena coloris?"

Turkey, Persia, India, and China have, I fear, in many cases, sacrificed taste to cheapness, and harmony to splendour in colour. It is a source of some satisfaction to know that the woad with which our ancient British predecessors stained their bodies is still cultivated among us for the purpose of dyeing wools, even though it has acquired the name of Isatis tinctoria and the colouring extract is now classed as an Indigotin.

"Among inorganic colours I may here briefly mention ultramarine, which instead of being patiently produced by the care ful treatment of lapis lazuli and sold at many shillings an ounce, is now manufactured by the ton and quoted by the hundredweight. Would that the artificial colour was as fine and permanent as the natural! I have, in my own time, seen it supersede smalts as a colouring matter in paper-making, and I have known its use not unfrequently accompanied by the abundant presence of sulphuretted hydrogen as a product of its decomposition.

"Not only colouring matters but our flavours and scents have been synthetised, though art, if superseding nature for a time, must eventually acknowledge her inferiority even in pear-drops. Whatever our æsthetic feelings under these circumstances may be, we cannot but admire the skill and scientific energy by which such results have been attained. How far 'saccharine,' one of the lastest results of the chemist's ingenuity, is likely to supersede the use of ordinary sugar, is a question on which I de. cline to speculate. The manufacture of our every-day sugar has, however, itself undergone a complete metamorphosis within the last fifty years, with the result that it is now produced at what would formerly have been regarded as an absolutely im. possible price. In 1840 , beet-sugar was in its infancy, and such has been the improvement in the growth of the beet and the process of manufacture that nearly twice the weight of sugar is now produced from a ton of beetroot as there was at that date. In the production of cane-sugar also immense economies have been effected, especially in the process of evaporation. The study of the effects of saccharine solutions on the polarisation No. 1238 , vor. 48$]$ of light, and our acquaintance with the distinctions between dextrose and levulose, and of the conversion of starch into sugar, all come within comparatively modern times.

"Much of our knowledge of the mysterious processes of fermentation is also of recent date, and it is in connection with these processes that the chemist finds himself brought into close contact with the botanist and the physiologist.

"Whatever suspicions Leeuwenhoek and the early microscopists may have had with regard to the vegetable character of yeastcells, and however clearly Cagniard de Latour and Schwann may have established its plant-like nature and its connection with fermentation, it was not until Pasteur's researches from r 857 to 1861 that the true character of the yeast-plant, and of other micro-organisms which lie at the base of most fermentative processes, can be said to have been absolutely demonstrated. The beneficial effect of his inquiries, and of his methods of obtaining a pure cultivation of yeast, is universally recognised, and has reacted in the most remarkable manner on the brewing industry.

"But M. Pasteur's researches have also led to much wider results, as it has been mainly in consequence of his careful observations that the wonderful influence for good or for evil of organisms so minute as in some cases almost to defy the power of the microscope, has now been so fully recognised. The germtheory of the origin of many diseases meets with much more general acceptance than it did but a few years ago ; and though the bacilli and bacteria which are characteristic of some virulent diseases, such as anthrax, are only agents in certain fermentative processes by which poisonous matters are engendered, their existence and character seem to be placed beyond all doubt. The process of obtaining immunity from the action of these poisons by the gradual introduction of the virus into the animal system, thus rendering it insusceptible of receiving further injury from the same poison, has been successfully introduced, both among men and beasts, and hydrophobia and anthrax have been successfully combated.

"A recognition of the influence of germs has led to the introduction into surgery of that antiseptic system of treatment with which the name of Lister will always be associated, and which has done so much to diminish suffering and preserve life. While upon this topic I may just allude to another instance in which chemistry has come to the assistance of medical science, I mean in the production and investigation of those anæsthetic agents which play so important a part in modern surgery, and which have done so much to alleviate human suffering.

"But while the ferments produced by micro-organisms are on the one hand so pernicious, it is very doubtful whether, on the other, they are not equally beneficial, if it be really the case that such processes as digestion are in a great measure due to their action. How far the nitrification of the soil may be due to micro-organisms is a question not yet absolutely solved, though strong presumption has been raised of their being, at all events, potent factors in the case.

"Now that so many diseases have been traced to pathogenic organisms which are constantly present in water contaminated by sewage, the question of the vitality of these organisms and their germs has been rightly regarded as one of great public importance, and the Royal Society, in conjunction with the London County Council, has instituted an investigation into it, which is being diligently prosecuted both from the botanical and the chemical points of view. The remarkable power of light, whether that of the sun or electric, in sterilising the germs of some micro-organisms, already to some extent previously known, has been conclusively demonstrated by Prof. Marshall Ward.

"Much has been done of late years by chemists towards the purification of sewage with the view of rendering the effluents from the ultimate drains of our large municipalities as innocuous as possible, and the results obtained have been in many instances satisfactory. They would, no doubt, have been even more so had not the imperative demands of economy limited the cost. Still, whatever may be done, I am inclined to think that there is much truth in the metrical abstract of a paper read some years ago before the Royal Society :-

$$
\begin{aligned}
& \text { "Sewage, however disinfected, } \\
& \text { Is not from ill results protected; } \\
& \text { The ugll made to all appearance pure, } \\
& \text { It still remains not safe, but sewer." }
\end{aligned}
$$

"I will not attempt to discuss the important question of the disposal of the sewage of our great towns, but to many it will appear as somewhat of a disgrace to our powers of applying chemical 
knowledge, that such vast accumulations of what were originally highly fertilising substances should be discharged into the estuary of the Thames, and not only be absolutely wasted, but converted into a perpetual nuisance, brought up at each tide within the limits of the metropolis from which they started.

"It is true that within the last fifty years we have imported enormous quantities of guano, phosphates, and nitrates, but of these there wust eventually become a scarcity, if not an end. In the meantime, may not chemists do something to reduce the waste of fertilising agents that is now taking place among us? Agricultural colleges have been founded-agricultural chemistry is a recognised branch of science; but with increase of knowledge has come increase of foreign competition, fostered by improved means of transport and communication, and it is at the present time a doubtful point whether many soils, even if rent-free, can be cultivated in this country for cereals, except at a loss.

"While touching on agricultural chemistry, I cannot pass over in silence the experiments which have now been carried on continuously for a period of fifty years at Rothamsted, by Sir John B. Lawes, assisted during the whole half-century by Dr. Gilbert. The extremely liberal provision which, during his life-time, Sir John Lawes has made for the purpose of continuing and extending his experiments, would alone entitle him to a full measure of public gratitude. When, however, we consider the nature and extent of the experiments already conducted, we must feel that no expression of public estimation can be too high when, as will shortly be the case, the Rothamsted jubilee is celebrated. As to the results already obtained, and as to the nature of the experiments still being carried on, it would be out of place here to enlarge. Remarkable, however, as are the effects of different manures on the botanical character and growth of herbage, and on the strength and yield of cereals, the different results arising from the mere variation of the temperature, sunshine, and rainfall, in successive years, are more remarkable still.

"I feel, however, that $\mathrm{I}$ have detained you long enough with these crude considerations of topics more or less chemical in their character, and that it is time for me to conclude.

"We are here assembled on the borders of the two counties of Lancashire and Cheshire, in both of which are great centres of chemical manufactures, and the principal productions of which are in a great degree dependent on the knowledge and due application of chemical laws. We meet at the seat of one of the most active sections of the Society of Chemical Industry, which has received us with open arms, and has provided us with an 'Open Sesame,' which will admit us to inspect many of the most interesting of the works and factories of the district. We gladly avail ourselves of the opportunities thus liberally opened to us, and if by chance any of us can afford assistance, advice, or encouragement to our brethren in Liverpool, I am sure that all present will gladly render it, and not forget that we are all members of one body, and all mutually interested in the advance of chemical knowledge, and especially of Chemical Industry.'

\section{THE PLAGUE OF FIELD VOLES.}

$\mathrm{R}$ ATHER more than a year ago a Committee was appointed by the Board of Agriculture to inquire into and report upon the circumstances attending the existing plague of voles in some of the southern counties of Scotland ; and to ascertain, either experimentally or otherwise, whether any, and if so what, preventive and remedial measures could be adopted, and under what conditions those measures were likely to be of value.

The committee consisted of Sir Herbert Eustace Maxwell, Bart., M.P. (chairman), the Right Hon. the Earl of Minto, K.T., the Rev. John Gillespie, Prof. D'Arcy W. Thompson, and Mr. Walter Elliot.

Mr. J. E. Harting, Librarian of the Linnean Society, acted as the Secretary to the Committee.

From the recently-published report we obtain the following information. "The animal, which by excessive multiplication has caused so much mischief on hill-farms in the southern uplands of Scotland, is the short-tailed field-vole (Arvicola agrestis). At all seasons it is a well-known inhabitant of our pastures and may be found at all heights from sea-level to near the summits of our highest mountains. It usually produces three or four litters a year, each consisting of from four to eight young, but in some seasons they are even more prolific, the breeding season is pro- longed, young voles being observed from February to Novem. ber, and the litters containing as many as ten young.

"The present outbreak may be traced back to the year 1888 , when the voles were observed to be increasing on the farm of Glenkerry and others in Selkirkshire. In the summer of 1889 the low.lying pastures near Closeburn, in Dumfriesshire, were observed to be infested by enormous numbers of voles, which remained there during $18 \mathrm{go}$, and disappeared in $189 \mathrm{I}$, probabiy moving up to the hill pastures, where in June 1892 they were swarming.

"The districts principally affected are the hill pastures in the north-west of Roxburghshire, the south of the counties of Selkirk, Peebles, and Lanark, and the northern part of Dumfries from Eskdalemuir by Moffat to Thornhill. The voles have also appeared in great numbers in the parishes of Dalry and Carsphairn, in the stewartry of Kirkcudbright.

"Mr. R. F. Dudge on has estimated that in Roxburghshire 30,000 to 40, cco acres bad been affected, of which he considered 12, coo to 15,000 acres had been rendered useless; in Dumfriesshire 40,000 to 50,000 acres, and in the stewartry of Kirkcudbright IO,OCO to I2,000 acres were described by him as infested by voles."

"The map accompanying the report of the Committee shows that an area not less than 6co miles in length and from 12 to 20 miles, in breadth has been overrun.

We reprint the following conclusions and recommendations contained in the report.

"The Committee have reluctantly been led to the conclusion that they are unable to recommend any specific method of deal. ing with or putting an end to the present outbreak.

"It appears to be an instance of the power which small animals are well known to possess, of prodigiously rapid multiplication under favourable climatic conditions and with a plentiful supply of natural food.

"Experience shows that a combination of such favourable conditions will always tend to bring about a recurrence of the plague. That being so, it ought to be the endeavour of every farmer and shepherd to be on the alert, and report with out delay to the Jand agent, and to the secretary of the local farmers' club, or agricultural society, the first signs of the multiplication of vermin, so that palliative measures may at once be adopted, not on isolated farms, but everywhere throughout the district.

"The most effective measures appear to be periodical and timely burning of grass and heather, followed by active pursuit of the vermin by men using wooden spades and dogs. If this were promptly done in the early stages of the outbreak, it is quite possible that it might be averted altogether or greatly mitigated in severity.

"It is bardly necessary to point out that the proprietor of the land should be informed as soon as anyone else, because his keepers and others might be usefully employed in assisting to prevent what amounts, if unchecked, to a common calamity upon all classes connected with land.

"Where plantations of limited extent are attacked, pit-falls wider at the bottom than at the top and about $\mathrm{I} 8$ inches deep should be dug. The voles fall into them and cannot escape, and the ground is soon cleared of them in this way.

"The Committee cannot speak with approval of the use of poisoned grain, except where the area affected is very limited.

"Nor have they been able to come to any conclusion favourable to the adoption of Prof. Loeffler's method of destroying voles by means of bread saturated in a preparation of the bacillus typhi murium, or mouse typhus. The personal investigations made by the chairman and secretary in Thessaly (where in May I 892 Prof. Loeffler was employed at the expense of the Greek Government to combat the plague of field-voles then prevailing in that country) convinced them that the favourable reports circulated as to the complete success of the experiments have not been justified by the results. In certain parts of Thessaly the voles were reported by landowners and others to be as numerous in January 1893 as ever they were.

"The Committee readily admit that, when used in a fresh state, the bacilliferous fluid is an effective though somewhat dilatory poison for mice and voles, and bas this advantage over minera poisons that, as has been proved, it is innocuous to human and other forms of life.

"It has also been reported by Prof. Loeffler that the Scottish voles sent to him alive by instructions from the Committee have been found as susceptible of the mouse typhus bacillus as their

NO. I 238 , VOL. 48 ] 